\title{
\begin{tabular}{ll} 
Research Square & Preprints are preliminary reports that have not undergone peer review. \\
\hline & They should not be considered conclusive, used to inform clinical practice,
\end{tabular} or referenced by the media as validated information.
}

\section{Abnormal B Cell Compartment Associated With Tfh Cells in Children With Henoch-schonlein Purpura}

\section{Ning Zhang}

The First Affiliated Hospital of Jinzhou Medical University https://orcid.org/0000-0003-1945-4734

\section{Ge Tian}

First Affiliated Hospital of Jinzhou Medical University

\section{Yuanyuan Sun}

First Affiliated Hospital of Jinzhou Medical University

\section{Jing Pan}

First Affiliated Hospital of Jinzhou Medical University

\section{Wei Xu}

First Affiliated Hospital of Jinzhou Medical University

Zhe Li ( $\square$ lz2205@126.com )

First Affiliated Hospital of Jinzhou Medical University

\section{Research article}

Keywords: Henoch-Schonlein purpura, B cells, CXCR5, subsets, Tfh

Posted Date: July 20th, 2020

DOl: https://doi.org/10.21203/rs.3.rs-44338/v1

License: (c) (1) This work is licensed under a Creative Commons Attribution 4.0 International License. Read Full License 


\section{Abstract}

\section{Aim}

IgA-producing B cells were found to be associated with children diagnosed with Henoch-Schonlein purpura (HSP). The present study aimed to determine whether children with HSP possess abnormal B cell subsets.

\section{Methods}

A total of 14 children diagnosed with HSP, and age- and gender-matched healthy controls were enrolled in our study. Peripheral blood mononuclear cells were isolated, and the percentage of B cells subsets and Tfh cells were determined by flow cytometry. Finally, Spearman's correlation coefficient was used to analyze the correlation between the percentage of Tfh cells and B cell subsets.

\section{Results}

We found that the frequency of total B cells was significantly increased in children with HSP; however, the percentage of plasma cells was significantly lower in HSP children. A significant reduction in the count of naïve $B$ cells and an increase in class-switched B cells were found in children with HSP compared with healthy controls. We observed that the expression of C-X-C chemokine receptor type 5 (CXCR5) on total $\mathrm{CD} 4^{+} \mathrm{T}$ cells and the percentage of $\mathrm{CD} 4^{+} \mathrm{CXCR} 5^{+}$cells were significantly increased within HSP patients. Moreover, significant correlations between Tfh cells and various $B$ cells subsets were observed.

\section{Conclusion}

Our study showed a Tfh cell-associated abnormal B cell compartment in HSP children.

\section{Introduction}

Henoch-Schonlein purpura (HSP), the most common type of childhood vasculitis, is characterized by the deposition of systemic IgA immune complexes in the walls of small vessels (1); it is estimated that $1 / 5000$ children acquire HSP per year (2). Although considered to be a self-limiting condition, HSP is manifested by skin purpura, arthritis, abdominal pain and renal involvement; the exact pathogenesis of HSP remains unknown.

HSP is a systemic inflammatory disease that has exhibited a correlation between immune index and leucocyturia, hematuria and proteinuria. Inflammatory cytokines, such as interleukin (IL)-6, IL-10 and IL17 , were reported to be involved in the pathogenesis of $\operatorname{HSP}(3-5)$. In addition, elevated serum IgA and 
IgA-related immune complexes were reported to play an essential role in the pathogenesis of HSP. Recently, IgA-producing B cells were also found to be related to children with $\operatorname{HSP}(6)$.

Dysregulated B cell subpopulations were found in a variety of autoimmune diseases, such as IgG4related disease and primary Sjögren's syndrome(7). The production of high-affinity antibodies results from the interactions between B cells and T follicular helper ( $T f h$ ) cells; an increased number of circulating Tfh cells has been correlated with the severity of autoimmune diseases $(8,9)$.

Whether children with HSP possess abnormal B cell subsets remains unknown. Therefore, in the present study, we sought to determine differences in the population of B cells and related subsets between children with HSP and healthy control patients. Our results may provide insight into the potential role of $B$ cell subsets and circulating Tfh cells in the pathogenesis of HSP.

\section{Materials And Methods}

\section{Clinical Demographics}

A total of 14 children diagnosed with HSP, and age- and gender-matched healthy controls (HCs) from May 2017 to March 2018 in The First Affiliated Hospital of Liaoning Medical University (Jinzhou, China) were enrolled in our study. The average age of all patients was 7.5 \pm 2.1 -years-old and 7.2 \pm 1 .9-years old of healthy controls. The gender ratio of HSP patients and HCs was $8 / 6$ and $7 / 7$ (male/female), and the average count of white blood cells was $11.5 \pm 2.3$ and $6.5 \pm 1.8$, respectively. The basic characteristics of HSP patients and HCs are present in Table I. All HSP patients and were diagnosed according to the modified criterion of HSP(10), in brief, all the included HSP patients diagnosed is based on the presence of purpura or petechiae with lower limb predominance plus at least one of the flowing four features: (1) abdominal pain; (2) arthritis or arthralgia; (3) leukocytoclastic vasculitis or proliferativeglomerulonephritis with predominant deposition of IgA on histology; (4) renal involvement. Exclusion criteria: all the included HSP patients did not suffer from any other diseases within the last 6 months prior to enrolment into the present study. Written informed consent was obtained from enrolled children or their legal guardians. The study was approved by the ethics committee of the First Affiliated Hospital of Jinzhou Medical University.

\section{Isolation of Peripheral Blood Mononuclear Cells (PBMCs)}

Fresh blood samples were obtained from HSP and HC patients; samples were diluted 1:1 with Hanks' solution and carefully layered on Ficoll-Hypaque for the formation of density gradients. The interphase cell layer was transferred into new tubes after centrifugation at $800 \mathrm{~g}$ for $20 \mathrm{~min}$ at room temperature (RT). The cells were then washed with Hanks' solution twice. The viability of the isolated PBMCs was determined by trypan blue exclusion staining, the total viability of PBMCs was reported as $>95 \%$.

\section{Flow Cytometry}

Fluorescein isothiocyanate (FITC)-conjugated anti-human cluster of differentiation (CD)19 (Cat\# 302206), C-X-C chemokine receptor type 5 (CXCR5; Cat\# 356914), phycoerythrin (PE)-conjugated CD27 
(Cat\# 302808), CD3 (Cat\# 317308), peridinin-chlorophyll-protein (PerCP)-Cy5.5-conjugated programmed cell death protein 1 (PD-1; Cat\# 329914), IgD (Cat\# 348208), allophycocyanin (APC)-conjugated CD4 (Cat\# 357407), CD38 (Cat\# 356606), APC-Cy7-conjugated CD3 (Cat\# 300426) and indicated isotype control FITC-conjugated Mouse IgG1, к (Cat\# 400108), PE-conjugated Mouse IgG1, K (Cat\# 400112), PEconjugated Mouse IgG2a, $\mathrm{K}$ (Cat\# 400211), PerCP-Cy5.5-conjugated Mouse IgG1, K (Cat\# 400150), PerCP-Cy5.5-conjugated Mouse IgG2a, k (Cat\# 400251), APC-conjugated Rat IgG2b, k (Cat\# 400611), APC-conjugated Mouse IgG1, k (Cat\# 400122), APC-Cy7-conjugated Mouse IgG1, к (Cat\# 400128) antibodies were purchased from BioLegend, Inc. (San Diego, CA, USA). Anti-CD16/32 antibody was added to the isolated lymphocytes to inhibit the Fc receptor at RT for 10 minutes. After incubation with the antibodies at RT for 15 minutes, the cells were washed and data were collected using a BD FACS Aria II flow cytometer (BD Biosciences, Franklin Lakes, NJ, USA). FlowJo Software (FlowJo LLC, Ashland, OR, USA) was used for data analysis.

\section{Statistical Analysis}

SPSS 21.0 software was used for data analysis. A Student's $t$ test was applied to determine significance between two groups. Spearman's correlation coefficient was used for analyzing the correlation between variables. $\mathrm{P}<0.05$ was considered statistically significant.

\section{Results}

\section{Frequency of Expanded B cells in Children with HSP}

To investigate the potential role of B cells in children with HSP, we isolated PBMCs from HSP and HC patients; the total variability of PBMCs was reported as $>95 \%$. We analyzed the percentage of total $\mathrm{CD}^{-} \mathrm{CD} 19^{+} \mathrm{B}$ cells, as well as B-cell-related subsets, such as plasma cells $\left(\mathrm{CD} 27^{++} \mathrm{CD} 38^{++}\right)$, naïve $\mathrm{B}$ cells $\left(\operatorname{lgD}{ }^{+} \mathrm{CD} 27^{-}\right)$, class-switched $B$ cells $\left(\operatorname{lgD}{ }^{+} \mathrm{CD} 27^{+}\right)$and memory B cells $\left(\operatorname{lgD}{ }^{-} \mathrm{CD} 27^{+}\right)$(Fig. 1$)$. As shown in Fig. 2A, the frequency of total $B$ cells was significantly increased in children with HSP compared with the control group $(p<0.05)$; however, the percentage of plasma cells was significantly lower in HSP children $(p<0.05$, Fig. 2B). The percentage of naïve B cells was significantly decreased, while that of classswitched B cells was significantly increased in children with HSP. There was no significant difference in the number of memory B cells between HSP and HC children (Fig. 2C). Collectively, we speculated that the development of abnormal B cell subsets may occur in children with HSP.

\section{Increased Expression of CXCR5 on CD4 ${ }^{+} \mathrm{T}$ cells in Children with HSP}

Tfh cells, which provide specialized cognate help to B cells, were characterized as CXCR5- and PD-1positive by flow cytometry. Next, we sought to determine whether the number of peripheral Tfh cells was increased by flow cytometry (Fig. 3). We observed a decreased percentage of total $\mathrm{CD} 3^{+}$and $\mathrm{CD} 4^{+} \mathrm{T}$ cells, but not for that of $\mathrm{CD} 8^{+} \mathrm{T}$ cells in HSP children compared with the control group (Fig. 4A). Both CXCR5 expression on total $\mathrm{CD} 4^{+} \mathrm{T}$ cells and the percentage of $\mathrm{CD} 4^{+} \mathrm{CXCR} 5^{+}$cells were significantly increased in 
HSP patients (Fig. 4B). However, neither PD- 1 expression on $\mathrm{CD} 4^{+} \mathrm{CXCR} 5^{+}$cells nor the percentage of $\mathrm{CD} 4^{+} \mathrm{CXCR}^{-}$cells significantly differed between HSP and HC patients (Fig. $4 \mathrm{C}$ ).

\section{The Correlation of B cell Subsets and Tfh cells in Children with HSP}

We measured the percentage of B cells proportions in total 14 included patients. However, for some unexpected reasons, we did not acquire the data of Tfh cells from one patient. Therefore, the sample size of Fig. 5A-C was 13. The percentage of CD24 ++CD38 ++ plasma cells from another two patients was nearly 0 , therefore we excluded the data of another two patients in Fig. 5D. Correlation analysis revealed the percentage of $\mathrm{CD} 4^{+} \mathrm{CXCR} 5^{+}$cells to significantly correlate with the percentage of total $\mathrm{CD} 3^{-} \mathrm{CD} 19^{+} \mathrm{B}$ cells (Fig. 3A). Furthermore, CXCR5 expression on total $\mathrm{CD} 4^{+} \mathrm{T}$ cells and the percentage of $\mathrm{CD} 4^{+} \mathrm{CXCR} 5^{+}$ cells significantly correlated with the percentage of naïve B cells $\left(\operatorname{lgD}{ }^{+} \mathrm{CD} 27^{-}\right)$, class-switched $B$ cells $\left(\operatorname{lgD}{ }^{+} \mathrm{CD} 27^{+}\right)$and memory B cells $\left(\operatorname{lgD}^{-} \mathrm{CD} 27^{+}\right)$; however, no correlation with plasma cells was observed(Fig. 5). Moreover, we did correlate B or Tfh cells with the clinical severity of HSP, but no significantly difference was observed (data not shown).

\section{Discussion}

Emerging evidences have shown that HSP within children is a systemic disease; however, the pathogenesis of HSP remains unknown. Functional mutations of T cells, such as abnormal cytokine secretion, were reported to be involved in the pathogenesis of $\operatorname{HSP}(11)$. Abnormal B cell activation with increased IgA secretion indicated that humoral immunity underlies the manifestations of HSP; however, whether abnormal B cell development and Tfh-dependent B cell responses play a role in the pathogenesis of HSP remain unknown.

In the present study, we enrolled children diagnosed with HSP, as well as HCs; the percentage of total $\mathrm{CD}^{+} \mathrm{CD} 19^{-} \mathrm{B}$ cells in each group was determined by flow cytometry. We found that the percentage of total B cells was significantly increased in children with HSP compared with HC patients. However, the percentage of $\mathrm{CD} 27^{++} \mathrm{CD} 38^{++}$plasma cells was significantly reduced in children with HSP.

To the best of our knowledge, no studies have been conducted to investigate the populations of total B cells and plasma cells in association with HSP. Our study is the first to reveal an expansion of total B cells and a reduced frequency of plasma cells in children with HSP. Further study was still needed to discover the detail mechanisms.

Functionally distinct B cell subsets can be divided into different subsets by the phenotypic expression of $C D 27$ and $\operatorname{lgD}$. IgD ${ }^{+} C D 27^{-} B$ cells were defined as naïve $B$ cells, whereas $C D 27$ expression by $B$ cells has been considered as a hallmark for somatic hypermutation and memory. $\mathrm{CD} 27^{+}$memory $\mathrm{B}$ cells can also be divided into pre-switch $\left(\operatorname{lgD}{ }^{+} \mathrm{CD} 27^{+}\right)$and post-switch $\left(\operatorname{lgD}{ }^{-} \mathrm{CD} 27^{+}\right)$B cell subsets. We sought to determine whether differences in the B cell compartment occur in HSP children and our results showed that the percentage of naïve B cells was significantly reduced, while that of class-switched B cells was 
significantly increased in children with HSP. Our results indicated that the abnormal development of B cells might be related to abnormal B cell responses in children with HSP.

A large number of studies have shown that Ig production was associated with the frequency of Tfh cells in a variety of autoimmune diseases, such as rheumatoid arthritis and systemic lupus erythematosus. In the current study, the percentage of $\mathrm{CD}^{+}, \mathrm{CD}^{+}$and $\mathrm{CD} 8^{+} \mathrm{T}$ cells was determined. In accordance with previous reports, our results showed that the frequency of $\mathrm{CD} 3^{+}$and $\mathrm{CD} 4^{+} \mathrm{T}$ cells was significantly decreased in children with HSP compared with HCs. CXCR5, a marker of Tfh cells, mediates the migration of Tfh cells to $B$ cells within follicular areas containing germinal centers. We showed significant increases in the expression of CXCR5 on CD $4^{+} T$ cells and the total frequency of $C X C R 5^{+} C D 4^{+}$Tfh cells in children with HSP compared with HC patients. PD-1, a functional marker of Tfh cells, exhibited no differences in expression between the two groups. A similar finding reported an expansion of circulating Tfh cells in children with acute HSP; a significant increase in CXCR5 ${ }^{+} \mathrm{CD} 4^{+}$cells in children with HSP and no differences in PD-1 expression between two groups were noted(12). Moreover, correlations between Tfh cells and naïve B cells, and class-switched B cell subsets, as well as memory B cells, were found in children with HSP in our study. We speculated that the HSP patients employed in our study may not exhibit an acute form of this disease as shown by the variations in their symptoms. Therefore, increased efforts should be made to classify HSP into different subtypes and the potential relationship between the frequency of $\mathrm{CXCR} 5^{+} \mathrm{CD} 4^{+}$Tfh cells and IgA-producing B cells should be explored.

This study has some potential limitations. The sample size of this study is small, which may lead to statistical bias. Large scale studies in HSP children are required in order to address this potential limitation.

In summary, our study showed abnormal B cell subsets and a Tfh cell-related abnormal B cell compartment in children with HSP. Our findings may provide a new insight into the pathogenesis of children with HSP. 
Table 1

Demographic and Clinical Characteristics of HSP

patients and $\mathrm{HCs}$

\begin{tabular}{|lll|}
\hline & HSP & HCs \\
\hline Number & 14 & 14 \\
\hline Age (years) & $7.5 \pm 2.1$ & $7.2 \pm 1.9$ \\
\hline Sex $(M / F)$ & $8 / 6$ & $7 / 7$ \\
\hline WBC $\left(\cdot 10^{9}\right)$ & $11.5 \pm 2.3$ & $6.5 \pm 1.8$ \\
\hline Serum $\operatorname{lgA}(g / d L)$ & $1.98 \pm 0.92$ & $1.77 \pm 0.53$ \\
\hline Serum $\operatorname{lgG}(g / d L)$ & $10.56 \pm 3.42$ & $9.34 \pm 2.52$ \\
\hline Serum $\operatorname{lgM}(g / d L)$ & $1.45 \pm 0.51$ & $1.13 \pm 0.47$ \\
\hline & & \\
\hline
\end{tabular}

\section{Declarations}

\section{Acknowledgements}

This work was supported by Liaoning Provincial Natural Science Foundation Project (No. 20180550988)

\section{Author Contributions}

Ning Zhang \&Zhe Li designed the projects and wrote the manuscript;Ning Zhang, Ge Tian\&Yuanyuan Sun did the experiments; Jing Pan\& Wei Xuprovided clinical samples. All the authors discussed and approved the manuscript.

\section{The authors declare no complete of interests.}

\section{References}

1. Basaran O, Cakar N, Uncu N, Celikel BA, Kara A, Cayci FS, et al. Plasma exchange therapy for severe gastrointestinal involvement of Henoch Schonlein purpura in children. Clin Exp Rheumatol. 2015;33:-176.

2. Chen JY, Mao JH. Henoch-Schonlein purpura nephritis in children: incidence, pathogenesis and management. World journal of pediatrics: WJP. 2015;11:29-34.

3. Jen HY, Chuang YH, Lin SC, Chiang BL, Yang YH. Increased serum interleukin-17 and peripheral Th17 cells in children with acute Henoch-Schonlein purpura. Pediatric allergy immunology: official publication of the European Society of Pediatric Allergy Immunology. 2011;22:862-8.

4. Yi H. [Effect of Shenyankangfu tablet on urinary IL-6 and its therapeutic effect in children with Henoch-Schonlein purpura nephritis]. Zhongguo dang dai er ke za zhi = Chinese. journal of 
contemporary pediatrics. 2007;9:153-4.

5. Yang B, Tan X, Xiong X, Wu D, Zhang G, Wang M, et al. Effect of CD40/CD40L signaling on IL-10producing regulatory $B$ cells in Chinese children with Henoch-Schonlein purpura nephritis. Immunol Res. 2017;65:592-604.

6. Gonzalez-Gay MA, Blanco R, Castaneda S. Henoch-Schonlein purpura (IgA vasculitis): the paradox of the different incidence and clinical spectrum in children and adults. Clin Exp Rheumatol. 2017;35(Suppl 103):3-4.

7. Lin W, Jin L, Chen H, Wu Q, Fei Y, Zheng W, et al. B cell subsets and dysfunction of regulatory B cells in IgG4-related diseases and primary Sjogren's syndrome: the similarities and differences. Arthritis research therapy. 2014;16:R118.

8. Nakayamada S, Tanaka Y. T follicular helper (Tfh) cells in autoimmune diseases. Nihon Rinsho Men'eki Gakkai kaishi = Japanese journal of clinical immunology. 2016;39:1-7.

9. Jeon YH, Choi YS. Follicular Helper T (Tfh) Cells in Autoimmune Diseases and Allograft Rejection. Immune network. 2016; 16:219 - 32.

10. Yang $\mathrm{YH}, \mathrm{Yu} \mathrm{HH}$, Chiang BL. The diagnosis and classification of Henoch-Schonlein purpura: an updated review. Autoimmun rev. 2014;13:355-8.

11. Huang DL, Xu ZC, Dang XQ, Zeng XQ, He XJ, Yi ZW, et al. [Relationship between renal Th1/Th2 ratio and renal microvascular injury in children with Henoch-Sch-nlein purpura nephritis]. Zhongguo dang dai er ke za zhi $=$ Chinese. journal of contemporary pediatrics. 2011;13:273-7.

12. Xie J, Liu Y, Wang L, Ruan G, Yuan H, Fang H, et al. Expansion of Circulating T Follicular Helper Cells in Children with Acute Henoch-Schönlein Purpura. Journal of Immunology Research. 2015; 2015:19.

\section{Figures}




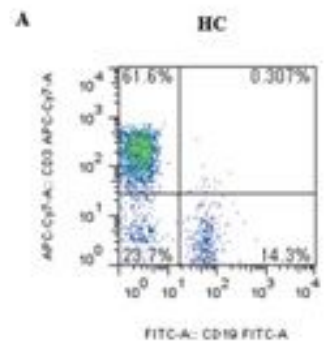

c
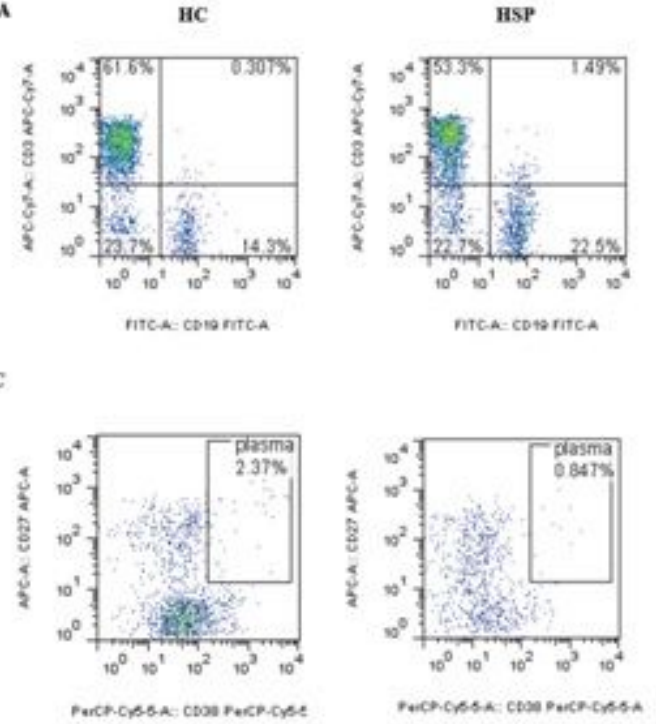

ntca-cotaritea
B

D
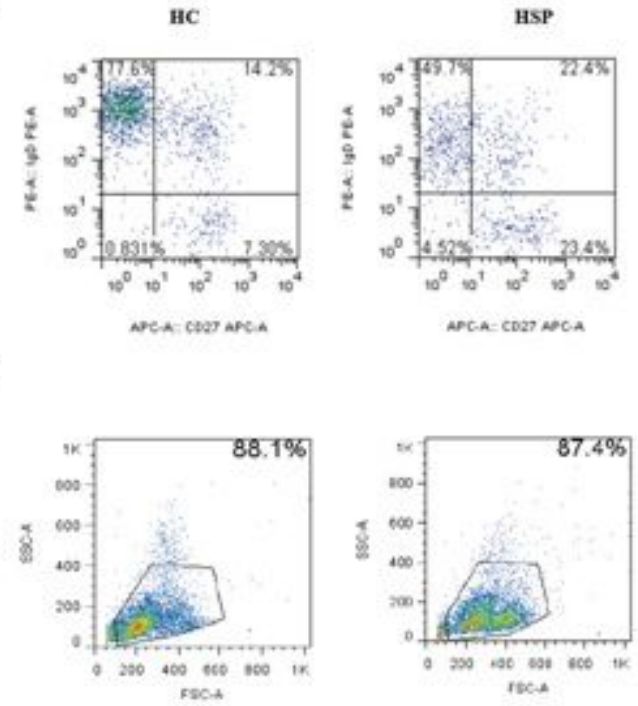

Figure 1

Flow cytometry analysis of the B cell compartment in children with HSP The percentage of (A) CD3CD19+ total B cells, (B) naïve B cells (IgD+CD27-), class-switched B cells (IgD+CD27+) and memory B cells (IgD-CD27+),and (C) CD27++CD38++ plasma B cells in children with HSP compared with HCs. (D) The purity of PBMCs from HCs and HSP children.CD: cluster of differentiation, HC: healthy controls, HSP, Henoch-Schonlein purpura.

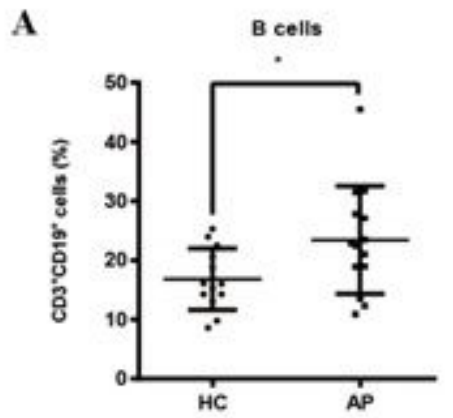

B

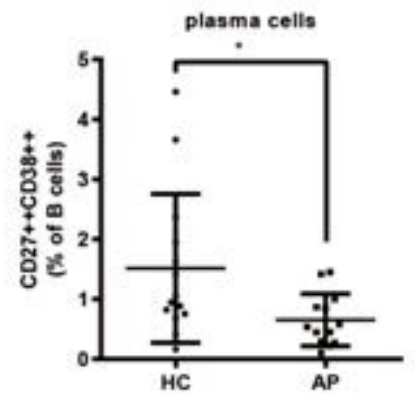

C
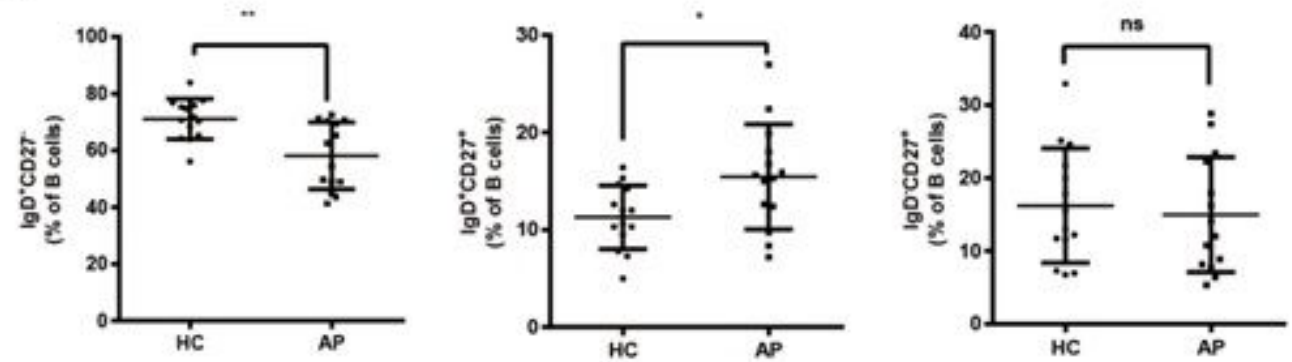

Figure 2 
Analysis of the frequency of $B$ cell subsets in children with HPS The percentage of (A) CD3-CD19+ total B cells, (B) CD27++CD38++ plasma B cells and (C) naïve B cells (IgD+CD27-), class-switched B cells $(\mathrm{IgD}+\mathrm{CD} 27+)$ and memory B cells (IgD-CD27+) in children with HSP compared with HC. Each plot represents anindependent individual. * $p<0.05 . \mathrm{CD}$ : cluster of differentiation, HC: Healthy controls,AP: Acute Henoch-Schonlein Purpura.

A

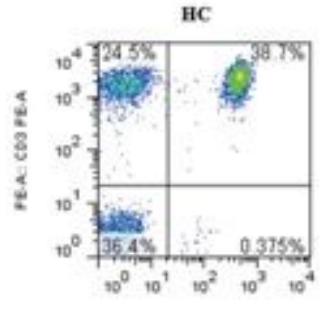

APCA CDA APCA

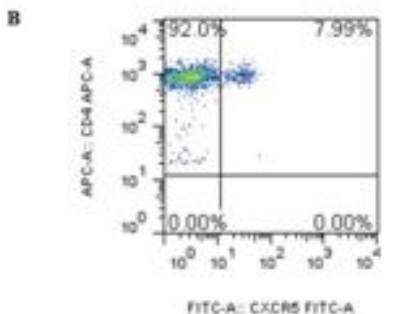

c

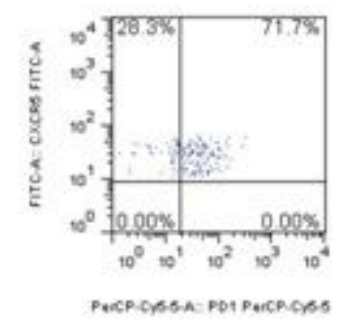

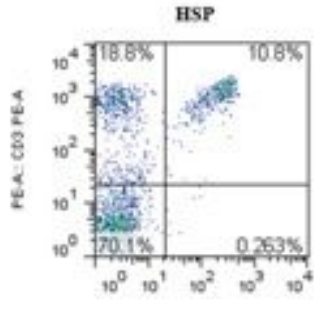

ApC.A: COA APCEA

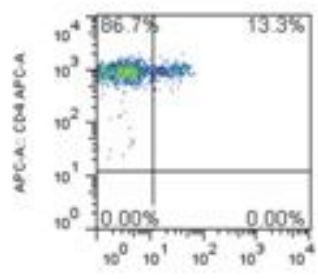

fitca: coches ritca

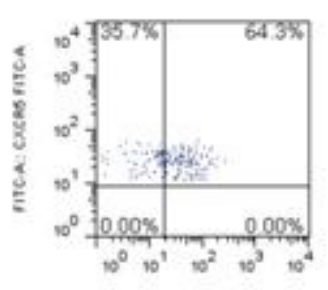

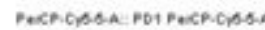

\section{Figure 3}

Analysis of the frequency of Tfh cells and PD-1 expression. Representative graph of the percentage of (A) The percentage of T cells, (B) CD4+CXCR5+Tfh cells and (C) PD-1 expression on Tfh cells in children with HSP and HCs.CD: cluster of differentiation, HC: Healthy controls, HSP, Henoch-Schonlein purpura, Tfh, T follicular helper. 
A
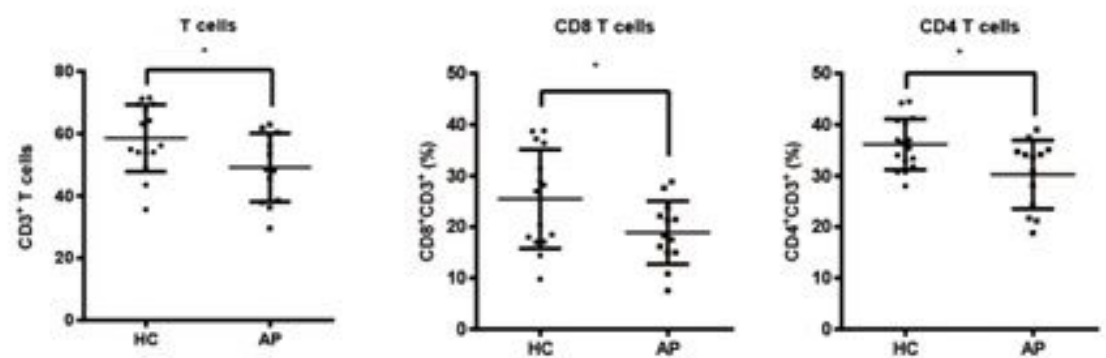

B

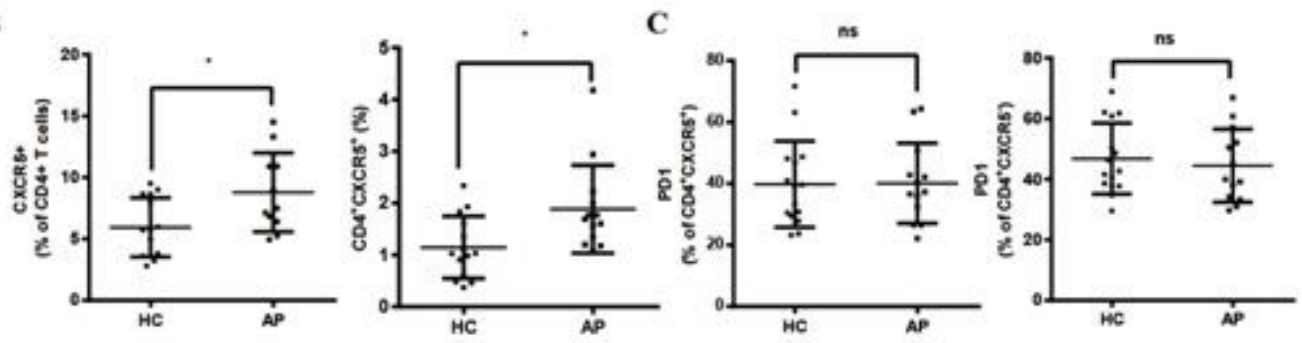

\section{Figure 4}

The frequency of Tfh cells and CXCR5 expression on total CD4+ T cells (A) The percentage of peripheral CD3+, CD4+ and CD8+ T cells in children with HSP. (B) CXCR5 expression on total CD4+ T cells and the percentage of Tfh cells in children with HSP. (C) PD-1 expression on CD4+CXCR5+ and CD4+CXCR5- cells in children with HSP compared with HCs. Each plot represents anindependent individual. * $p<0.05 . \mathrm{CD}$ : cluster of differentiation, CXCR5, C-X-C chemokine receptor type 5, HC: Healthy controls, AP: Acute Henoch-Schonlein Purpura, PD-1, programmed cell death protein 1, Tfh, T follicular helper.

$\mathbf{A}$
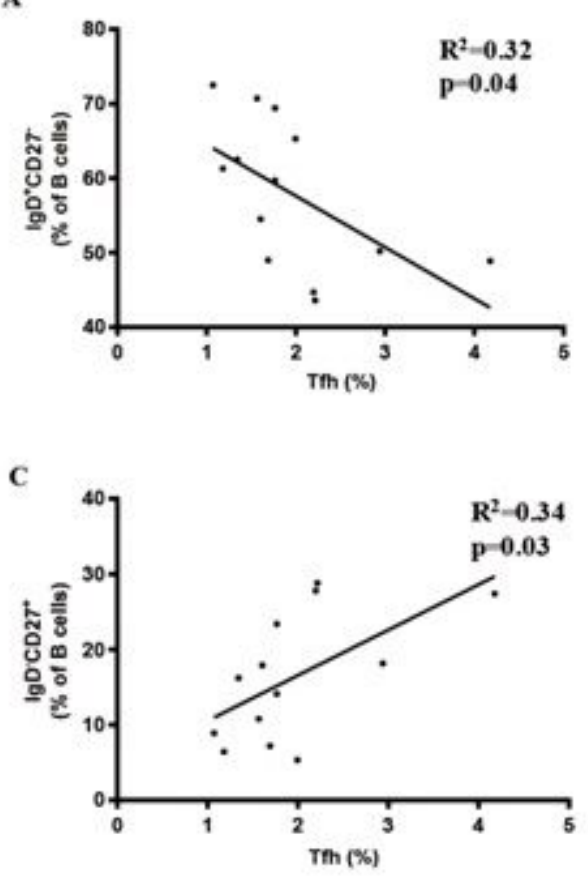

B

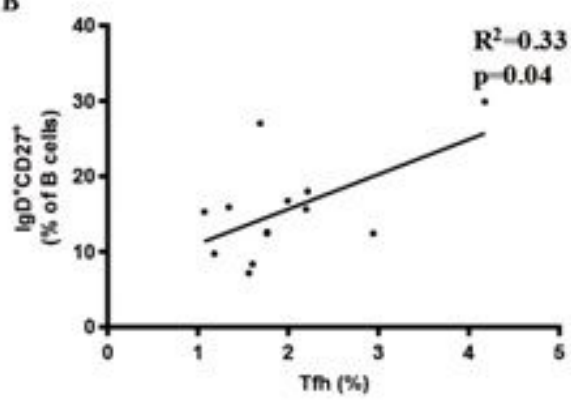

D

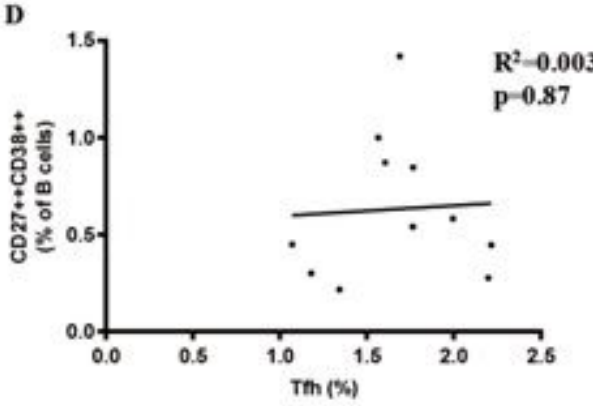


Correlation between of $B$ cells subsets andTfh cells. Correlation analysis of (A) IgD+CD27- B cells, (B) IgD+CD27+ B cells, (C) IgD-CD27+ B cells and (D) CD27++CD38++ plasma B cells with the percentage of CD4+CXCR5+Tfh cells or CXCR5 expression on total CD4+ T cells. CD: cluster of differentiation, CXCR5, C-X-C chemokine receptor type $5, \mathrm{Tfh}, \mathrm{T}$ follicular helper.

\section{Supplementary Files}

This is a list of supplementary files associated with this preprint. Click to download.

- Fig1S.jpg 